\title{
Otonom Sistemlerde Veri Çoğaltma Yöntemleri Kullanılarak İyileştirilmiş Gerçek Zamanlı Nesne Tespiti
}

\author{
Fırat Bozkaya $^{1 *}$, Abdullah Yusefi², Şükrücan Tığglığlu ${ }^{3}$, Ahmet Kağan Kaya ${ }^{4}$, Okan Kazanci ${ }^{5}$, Mustafa Yasin \\ Akmaz $^{6}$, Akif Durdu $^{7}$, Cemil Sungur ${ }^{8}$ \\ $1^{*}$ Konya Teknik Üniversitesi, Mühendislik Fakültesi, Bilgisayar Mühendisliği Bölümü, Konya, Türkiye, (ORCID: 0000-0002-4310-9490), ffbozkaya97@gmail.com \\ ${ }^{2}$ Konya Teknik Üniversitesi, Mühendislik Fakültesi, Bilgisayar Mühendisliği Bölümü, Konya, Türkiye, (ORCID: 0000-0001-7557-8526), a.yusefi1991@gmail.com \\ ${ }^{3}$ Konya Teknik Üniversitesi, Mühendislik Fakültesi, Bilgisayar Mühendisliği Bölümü, Konya, Türkiye, (ORCID: 0000-0003-3939-8987), sukru28980@gmail.com \\ ${ }^{4}$ Konya Teknik Üniversitesi, Mühendislik Fakültesi, Elektrik-Elektronik Mühendisliği Bölümü, Konya, Türkiye, (ORCID: 0000-0002-7845-7292), \\ kayakagan10@gmail.com \\ ${ }^{5}$ Konya Teknik Üniversitesi, Mühendislik Fakültesi, Bilgisayar Mühendisliği Bölümü, Konya, Türkiye, (ORCID: 0000-0002-6184-3349), okankazanci29@gmail.com \\ ${ }^{6}$ Konya Teknik Üniversitesi, Mühendislik Fakültesi, Bilgisayar Mühendisliği Bölümü, Konya, Türkiye, (ORCID: 0000-0002-3608-1290), \\ mustafa.akmaz19@gmail.com \\ ${ }^{7}$ Konya Teknik Üniversitesi, Mühendislik Fakültesi, Elektrik-Elektronik Mühendisliği Bölümü, Konya, Türkiye, (ORCID: 0000-0002-5611-2322), adurdu@ktun.edu.tr \\ ${ }^{8}$ Konya Teknik Üniversitesi, Mühendislik Fakültesi, Elektrik-Elektronik Mühendisliği Bölümü, Konya, Türkiye, (ORCID: 0000-0003-2340-6225), \\ csungur@ktun.edu.tr
}

(2nd International Conference on Computer, Electrical and Electronic Sciences ICCEES 2021, September 1-3, 2021)

(DOI: $10.31590 /$ ejosat.1006408)

ATIF/REFERENCE: Bozkaya, F., Yusefi, A., Tığlığlu, Ş., Kaya, A. K., Kazancı, O., Akmaz, M. Y., Durdu, A. \& Sungur, C. (2021). Otonom Sistemlerde Veri Çoğaltma Yöntemleri Kullanılarak İyileştirilmiş Gerçek Zamanlı Nesne Tespiti. Avrupa Bilim ve Teknoloji Dergisi, (30), 83-87.

\section{Öz}

İnsan müdahalesi olmadan çalışan sistemler savunma sanayi başta olmak üzere pek çok alanda gün geçtikte önemi ve kullanımı artmaktadır. Bu sistemlerde insan faktörü azaltılarak maliyet ve zamandan kazanç sağlansa da görüntü işleyerek çalışan sistemlerde doğruluk oranının yüksek olmaması durumunda yeni problemler ortaya çıkmaktadır. İnsan müdahalesi olmadan çalışan kara araçları için levha tespitindeki hatalı tespit problemleri, hava araçlarında ise iniş noktasının doğru tespit edilememesi gibi problemlerdir. Bu çalışmada hava aracından çekilmiş görüntüler kullanılmıştır. Bu görüntüler üzerinde çeşitli veri çoğaltma yöntemleri kullanılarak nesne tespit oranının arttırılmasıyla tespit problemlerinin giderilmesi üzerine çalışılmıştır. Veri çoğaltma yöntemlerinde Gaussian, karlanma, gölgelendirme, yüksek gama, Kontrast Sınırlı Uyarlanabilir Histogram Eşitleme (CLAHE), arttırılmış parlaklık, azaltılmış parlaklık yöntemleri uygulanarak veri çoğaltma işlemi yapılmış olup nesne tespitinde kullanılacak olan model eğitimi YOLOv4 algoritmasıla gerçekleştirilmiştir. Sonuçlar gözlemlendiğinde 8000 tekrar sonrasında başarı oranının \%94'e kadar çıktığı ve kayıp (loss) değerinin 0.42 sonucunu verdiği gözlemlenmiştir. Eğitilen model simülasyon ortamına gerek duyulmadan gerçek araçta denenmiştir.

Anahtar Kelimeler: Veri Çoğaltma, Nesne Tanıma, YOLOv4, Görüntü İşleme, İnsansız Hava Araçları

\section{Improved Real Time Object Detection In Autonomous Systems Using Data Augmentation Methods}

\begin{abstract}
The importance and application of systems that work without human involvement are growing in many industries, particularly in the defense industry. Although minimizing the human role in these systems saves money and time, it also introduces new challenges if the accuracy rate in image processing systems isn't high enough. Erroneous traffic sign detection for land vehicles running without human assistance, as well as a failure to correctly estimate the landing site in aircraft. In this study, images from the plane were collected and used to enhance object detection in autonomous systems. On these photos, several data augmentation approaches have been used to try to alleviate the detection challenges by increasing the object detection rate. Data reproduction methods included Gaussian, snow, shading, high gamma, Contrast Limited Adaptive Histogram Equalization (CLAHE), raised luminance, and lowered luminance methods, as well as data augmentation. The YOLOv4 algorithm was utilized to train the model for object detection. When the findings were examined, it was discovered that after 8000 repetitions, the success rate had increased to 94 percent, and the loss value had decreased to 0.42 . In addition to the simulation environment, the trained model was also evaluated in a real ground vehicle.
\end{abstract}

Keywords: Data Augmentation, Object Detection, YOLOv4, Image Processing, Unmanned Aerial Vehicles

* Sorumlu Yazar: ffbozkaya97@gmail.com 


\section{Giriş}

Günümüzde, insan müdahalesi olmadan çalışan (otonom) sistemler sıkça kullanılmaktadır. Çeşitli amaçlarla kullanılan otonom sistemler, geniş bir alana hitap etmektedir. Otonom sistemlerin temel amacı insan faktörünü azaltmaktır. İnsan faktörü ön planda tutulan sistemlerde maliyet ve zaman açısından dezavantaj oluşmaktadır. İnsan faktörünün azaltılmasıyla beraber zaman ve maliyetten kazanç sağlanmasının yanı sıra hatalarda minimum düzeye indirgenecektir. Otonom sistemlerin çoğu, bir ya da birden fazla kamera yardımıyla alınan görüntünün işlenmesiyle çalışmaktadır. Sistemin doğruluğu ise gelen görüntünün doğru bir şekilde işlenip işlenemediğine bağlıdır. Görüntünün işlenmesi kısmında doğruluk oranının yüksek olmaması durumunda yeni problemler ortaya çıkmaktadır. Bu problemlerden biri, otonom olarak hareket eden bir kara aracının yol kenarındaki levhaları yanlış bir şekilde tespit etmesidir. Örneğin, sola dönülmez levhasının yanlış şekilde tespit edildiği bir durumda otonom çalışan kara aracı sola dönebilir ve kaza yapma riski oluşturabilir. Hava araçlarında karşılaşılabilecek problemler arasında ise iniş noktasının doğru tespit edilememesi ve yanlış bir noktanın iniş noktası olarak tespit edilmesi halinde istenmeyen durumlara sebebiyet verebilir. $\mathrm{Bu}$ yanlış tespit problemleri nesne tespitindeki başarı oranı yükseltilerek önlenebilir. Bunun için hava aracından çekilmiş görüntüler kullanılmıştır. Bu çalışmada nesne tespitindeki başarı oranını yükseltebilmek için görüntüler üzerinde çeşitli veri çoğaltma yöntemlerinden faydalanılmıştır.

Veri çoğaltma yöntemlerinde Gaussian, karlanma, gölgelendirme, yüksek gama, Kontrast Sınırlı Uyarlanabilir Histogram Eşitleme (CLAHE) [1], arttırılmış parlaklık, azaltılmış parlaklık yöntemleri kullanılmaktadır. Yapılan bu çalışmada ağırlıklı olarak CLAHE yöntemi üzerinde durulmuştur. Ayrıca yapılan bu veri çoğaltma işlemlerinden sonra elde edilen veri setiyle beraber nesne tanımada kullanılacak olan model eğitimi, YOLOv4 [2] algoritmasıyla gerçekleştirilmiştir.

Bildirinin geri kalan kısmının ikinci bölümünde çalışmayı yaparken kullanılan görüntü kirletme algoritmaları, YOLOv4 algoritması yöntemlerinin anlatılmasının yanı sıra kullanılan materyaller ve literatür araştırması yapılmıştır. Üçüncü bölümde model eğitimi ve sonrasında ortaya çıkan bulgulara yer verilmiştir. Dördüncü bölümde çalışmayla ilgili gözlem ve sonuçlara yer verilmiştir. Beşinci bölümde ise çalışmada yararlanılan kaynaklar yer almaktadır.

\section{Materyal ve Metot}

\subsection{Görüntü Kirletme Algoritmaları}

Görüntü kirletme, veri setindeki çeşitliliği arttırmak amacıyla kullanılan veri çoğaltma işlemleridir. Karşılaşılabilecek farklı görüntü kırılmalarında (gölgelendirme, arttırılmış parlaklık, azaltılmış parlaklık vb.) modelin nesne tespitinde kullanılan veri seti çeşitliliğinin artmasıyla modelin tespit yeteneği doğru oranda artacaktır. Kullanılan görüntü kirletme yöntemleri Gaussian gürültüsü, karlandırma, gölgelendirme, gamma arttırma, güneş parlaklığını arttırma ve 1şık oranını azaltma olarak kullanılmıştır. Bunlara ek olarak CLAHE algoritması da görüntü kirletme algoritmalarıyla beraber model eğitimi için kullanılmıştır.

CLAHE algoritması görsellerdeki yerel kontrastı geliştiren bir algoritmadır. Böylelikle, veri setindeki renk farklılıkları azaltılabilmektedir. Bunlarla birlikte histogram eşitleme (HE) teknikleri de kullanılmaktadır. Histogram eşitleme tekniği, görüntünün kontrastını arttırmak için kullanılan yaygın bir yöntemdir. Uyarlanabilir Histogram Eşitleme (AHE) ise görüntünün bazı bölgelerine karşılık gelen birkaç histogramı hesaplayarak yerel kontrastı geliştirip yerel bilgi kaybını azaltmaktadır. CLAHE, HE ve AHE yöntemlerini baz alarak kontrastın limitlenmesini sağlar [1]. Böylece önceden verilen değerde histogramı kırpmasını sağlayarak büyümeyi önler. CLAHE algoritması, veriler içerisinden daha kaliteli görüntüler elde edilmesini sağlamaktadır. Nesne tespit modeli için veri seti oluştururken veri çeşitliliğini çoğaltmak amacıyla CLAHE algoritması kullanılarak daha kaliteli görüntü oluşturulmuştur. Orijinal görüntü ve CLAHE algoritması uygulanmış görüntü Şekil 1.a ve Şekil 1.b'de verilmiştir.

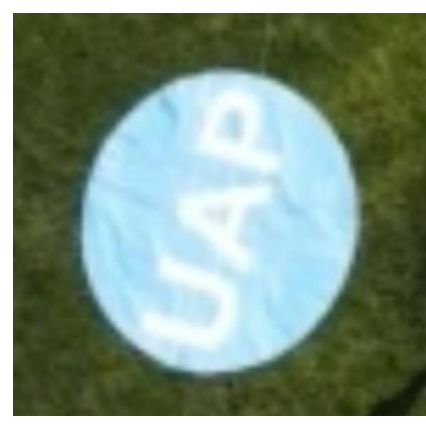

Şekil 1.a: Orijinal Görüntü

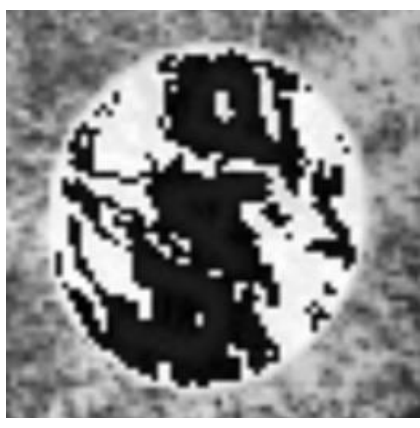

Şekil 1.b: CLAHE Uygulanmış Görüntü

Gaussian bulanıklaştırması ile görüntü üzerindeki gürültülerin azaltılması amaçlanmaktadır. Gürültünün çok olması durumunda tespit oranları düşmekte olup yanlış tespit ihtimali artmaktadır. Gaussian bulanıklaştırması kullanıldığında tespit oranları artmaktadır. Gaussian bulanıklaştırmasını kullanmak için iki boyutta Gauss fonksiyonu kullanılmaktadır. $\mathrm{Bu}$ fonksiyon aşağıda verilmiştir.

$$
G(x, y)=\frac{1}{2 \pi \sigma^{2}} e^{-\frac{x^{2}+y^{2}}{2 \sigma^{2}}}
$$

$\mathrm{Bu}$ fonksiyonda kullanılan $x$ ve $y$ parametreleri, merkez pikselden $(0,0)$ deltayı belirtir. Örneğin, çekirdek için seçilen yarı çap 3 ise $x$ ve $y-3$ ile 3 (dahil) arasında değişim göstermektedir. $\mathrm{Bu}$ fonksiyonda diğer bir parametre olan $\sigma$ ise standart sapmadır. Merkez pikselin, komşu piksellerinin hesaplama sonucunu ne kadar önemli ölçüde etkilediğini belirtir [3].

Karlandırma (snow) tekniği HLS [5] renk uzayındaki görüntünün açıklık artırma yöntemini kullanarak, çoğunlukla yollar, ağaçlar, dağlar ve diğer peyzaj özellikleri olan görüntünün en karanlık kısımlarını beyazlatır. Böylelikle görselde bulunan alanlarda karlanma varmış gibi bir görüntü elde edilir.

Gölgelendirme tekniği görüntü içerisindeki belirli alanlara rastgele olarak gölgeler ekler. Böylelikle tepelerde veya ormanlık alanda rastgele değişen parlaklık, doğru şekilde eğitilmemişse bu sorunun önüne geçilebilir.

Gamma değeri bir görüntünün kontrast ölçümüdür. Yüksek gamma değerinde kontrast değeri yüksekken düşük gamma değerinde ise kontrast değeri düşük olur. Gamma değerinin yükseltilmesi sayesinde kontrast artacak olup renkler arasındaki karşıtlık artacak; ayrıca görüntüdeki çizgiler, şeritler daha belirgin olacaktır.

Görüntünün parlaklık değerinin arttırılmasıyla resim üzerinde bulunan nesnelerin renkleri daha ön plana çıkacaktır. Aynı şekilde görüntünün parlaklık değeri azaltılırsa resim üzerinde bulunan nesneler daha koyu bir şekilde gözükecektir. Bu sayede veri sayısı 
artarak farklı 1şı miktarlarında tespit oranının arttığ gözlemlenmiştir.

Anlatılan görüntü kirletme yöntemleri Şekil 2'de ilgili resimlerde gösterilmiştir.
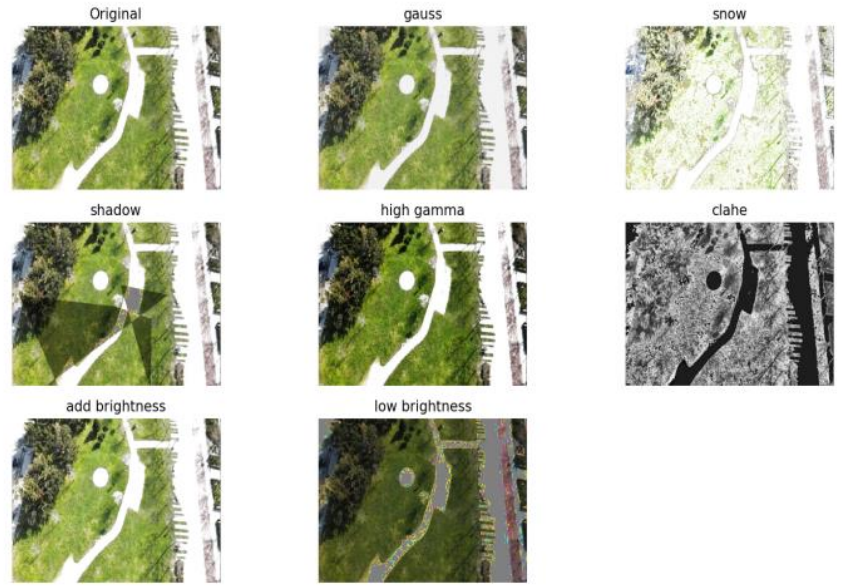

Şekil 2: Kirletme Algoritmalarının Uygulanması

\subsection{Konvolüsyonel Sinir A}

Konvolüsyonel sinir ağları (CNN) [6], derin öğrenmenin bir alt dalıdır ve genellikle görsel bilginin analiz edilmesinde kullanılmaktadır. Yaygın kullanım alanları resim ve video tanıma, öneri sistemleri, resim sınıflandırma, tıbbi görüntü analizi ve doğal dil işleme olarak sıralanabilmektedir. İleri yönlü bir sinir ağı olan konvolüsyonel sinir ağı algoritması, hayvanların görme merkezinden esinlenilerek ortaya atılmıştır. Buradaki matematiksel konvolüsyon işlemi, bir nöronun kendi uyarı alanından uyaranlara verdiği cevap olarak düşünülebilir. $\mathrm{CNN}$, bir veya daha fazla konvolüsyonel katman, alt örnekleme (subsampling) katmanı ve bunun ardından standart çok katmanlı bir sinir ağı gibi bir veya daha fazla bağlı katmandan oluşmaktadır [4]. Bu bağlı katmanların birbiriyle ilişkisi Şekil

gösterilmiştir.

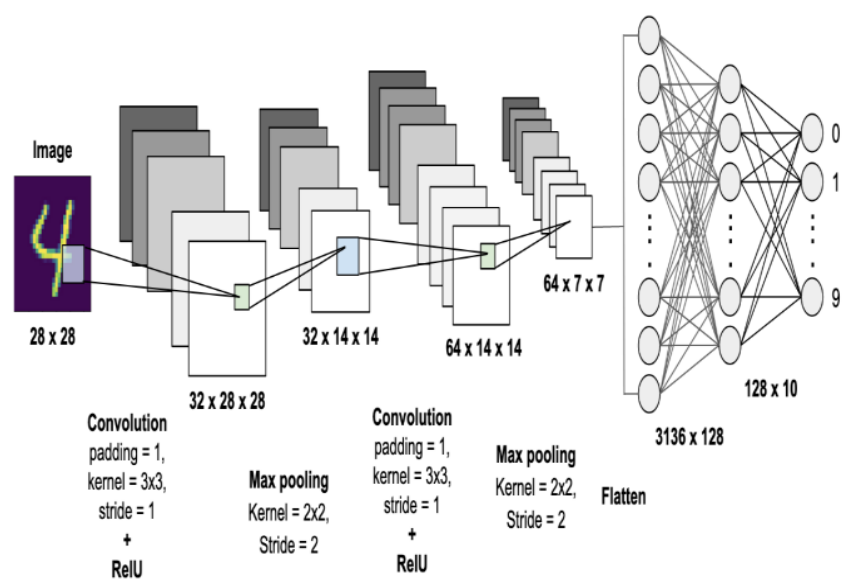

Şekil 3: Konvolüsyonel Sinir Ağı Katmanları

\subsection{YOLOv4 Algoritması}

YOLO, konvolüsyonel sinir ağları (CNN) üzerine kurulmuş olup, videolardan ve görüntülerden nesne tespiti yapabilen bir derin ögrrenme algoritmasıdır [2]. Bu algoritmada görüntüye bir sinir ağı uygulanır. Bu sinir ağı görüntüyü bölgelere ayırmaktadır ve her bölge için olasılıkları ve sınırlayıcı kutuları tahmin etmektedir. Bu sınırlayıcı kutular her bir bölgede nesne bulunma olasılığını hesaplar. Ayrıca her sınırlayıcı kutu için bir güven skoru da hesaplanmaktadır. Bu skor sayesinde o nesnenin yüzde kaç ihtimalle tahmin edilen nesne olduğunu ortaya çıkartmaktadır. Örneğin bulunan bir insan için güven skoru 0,2 ise o nesnenin insan olma olasılığı oldukça düşüktür. YOLO, yaptığı tahminin güvenilmez olduğunu güven skoru aracılığıyla belirtmektedir. Sinırlayıcı kutularda bulunan nesnelere Maksimum Olmayanı Baskılama (Non-Maximum Suppression) yöntemi [7] uygulanmaktadır. $\mathrm{Bu}$ işlem güven skorlarını karşılaştırarak güven skoru düşük olan nesneleri değerlendirmeden çıkartır ve aynı bölgede güven skoru daha yüksek olan bir sınırlayıcı kutu olup olmadığını kontrol eder. Daha yüksek bir sınırlayıcı kutu olması durumunda en yüksek güven skoru olanı işaretleyerek diğer sınırlayıcı kutuları görüntüden çıkarmaktadır. Bu sınırlayıcı kutular aracılığıyla nesne tespiti örneği Şekil 4 'te verilmiştir.

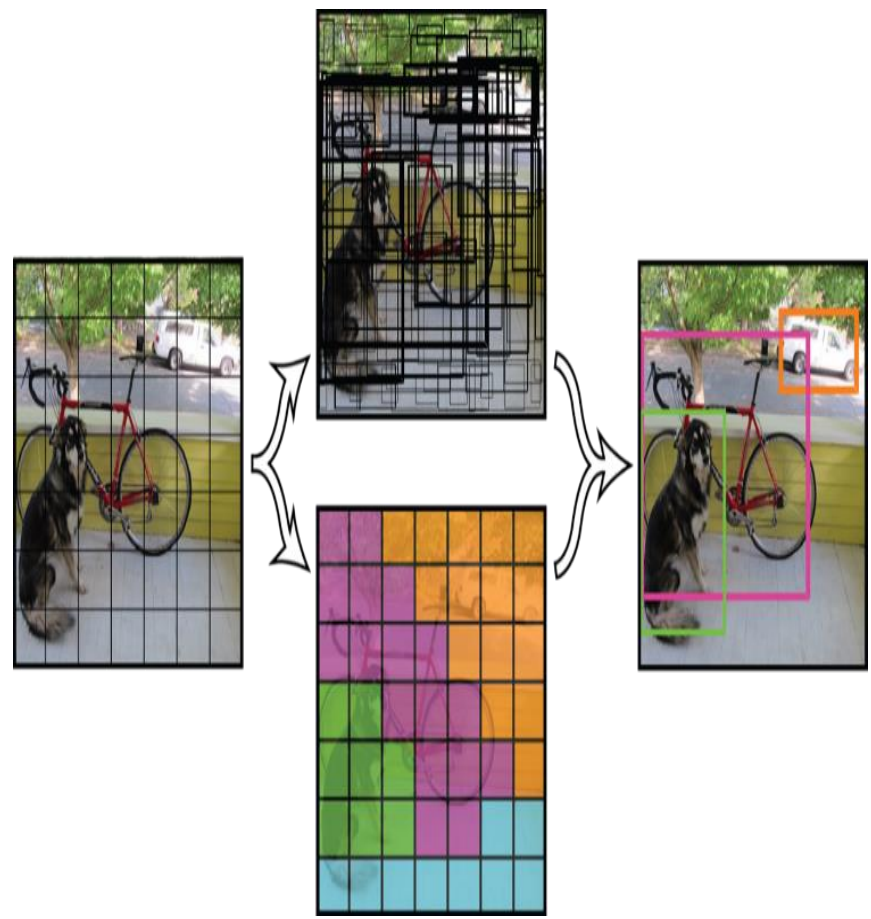

Şekil 4: Sınırlayıcı Kutular Aracılığıyla Nesne Tespiti

YOLOv4 modeli, nesne tanıma algoritmasının dördüncü sürümüdür. Bu sürüm önceki sürümlerde olduğu gibi hem bir kez konvolüsyonel sinir ağı modelinden geçmekte hem de MS-COCO veri kümesinden faydalanmaktadır. Bu sayede saniyede işlenen kare hızında ciddi bir artış olmakla beraber gerçek zamanlı nesne tespiti yapılmasına olanak sağlamaktadır.

\section{Araştırma Sonuçları ve Tartışma}

\subsection{Bulgular}

İnternet üzerinde bulunan hava aracının kaydettiği görüntüler kullanılarak bu görüntüleri Kısım 2.A'da bahsedildiği gibi çeşitlendirilerek YOLOv4 modelinde eğitim gerçekleştirilmiştir. Bu eğitimlerde RTX 2060 ekran kartı kullanılmış olup YOLOv4 modelinde eğitim 12 saat sürmüştür. Eğitim sonunda ağırlıklar incelendiğinde, düşük iterasyon sayısında oluşan ağırlıkların nesne tespitinde birden fazla sınırlayıcı kutu çizdiği görülmektedir. Nesne tespit oranının artması için aşağıda verilen matematiksel işlem uygulanmıştır.

Sınıf Sayısı $* 2000$ 
$\mathrm{Bu}$ alandaki sınıf sayısı tespit edilecek farklı nesne sayısıdır. Görüntü kirletme işlemleri uygulanmış ve uygulanmamış model üzerindeki örnek görüntüler Şekil 5.a-d'de verilmiştir. Şekil 5.ad'de yer alan sınıflar Uçan Araba Park (UAP), insan, Uçan Ambulans İniş (UAİ) alanıdır. Eğitilen modeller simülasyon ortamına gerek duyulmadan gerçek araçta denenmiştir.

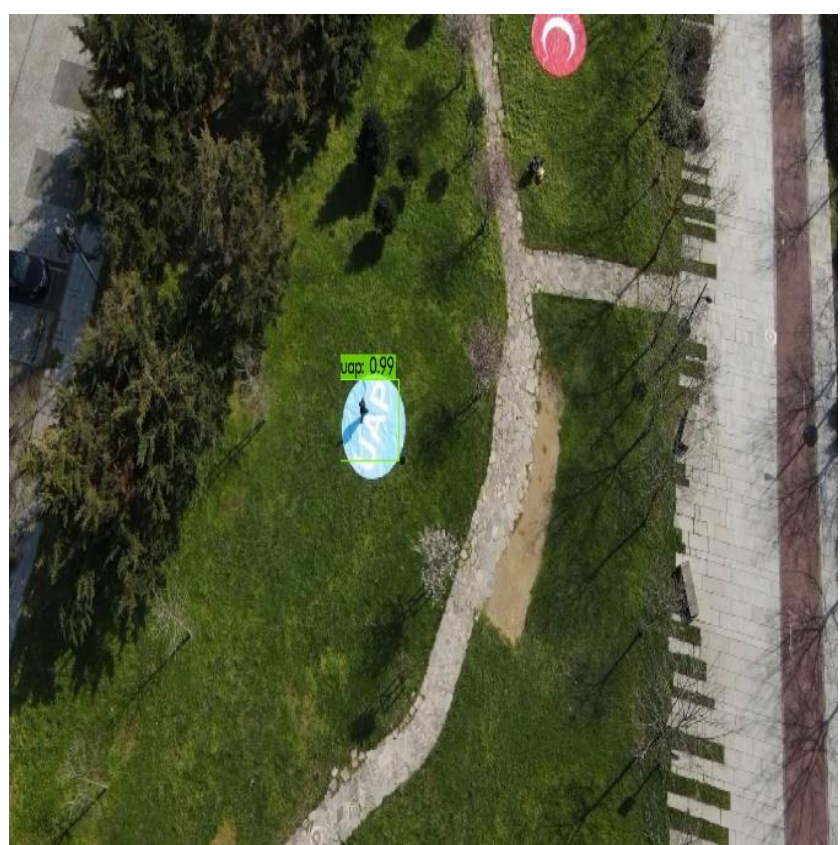

Şekil 5.a: Görüntü Kirletme Uygulanmamış Model

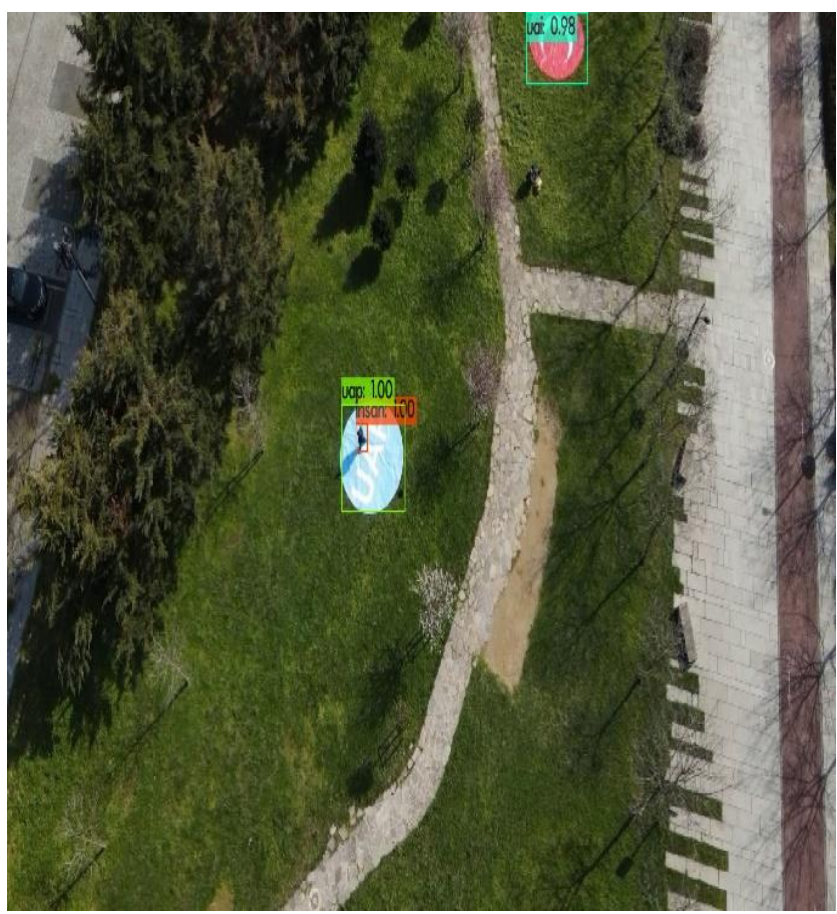

Şekil 5.b: Görüntü Kirletme Uygulanmış Model

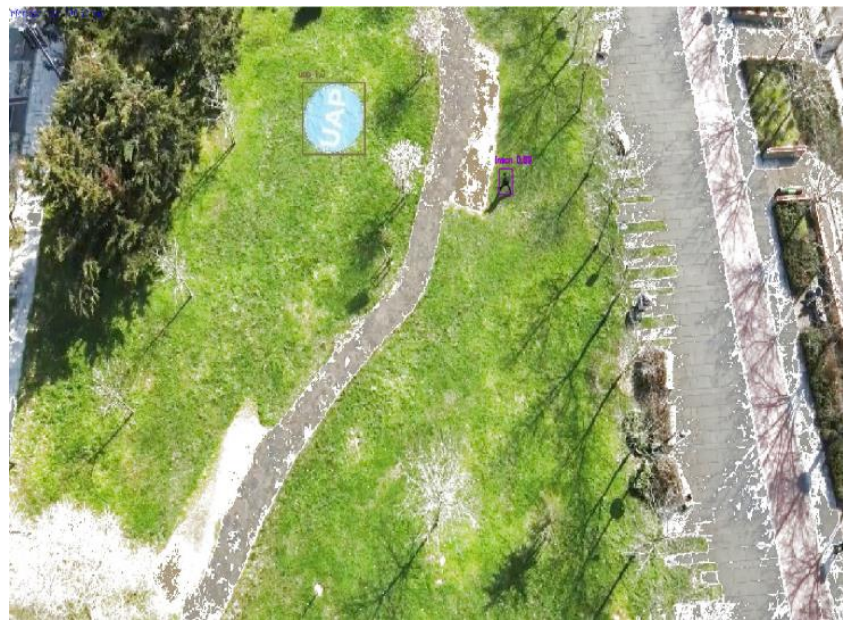

Şekil 5.c: Karlanmış Görsel Üzerinde Nesne Tespiti

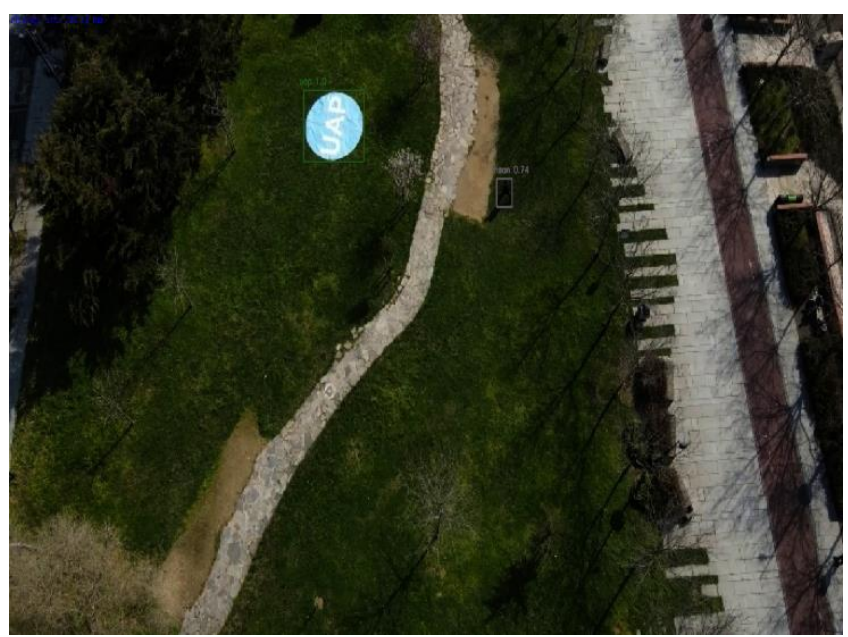

Şekil 5.d: Gama Uygulanmış Görsel Üzerinde Nesne Tespiti

Kullanılan YOLOv4 modelinin 8000 tekrar sonrasında başarı değerinin \%94'e kadar çıktığı ve loss değerinin 0.42 sonuç verdiği gözlemlenmiştir. Bu eğitim bilgileri Şekil 6'da gösterilmiş̧ir.

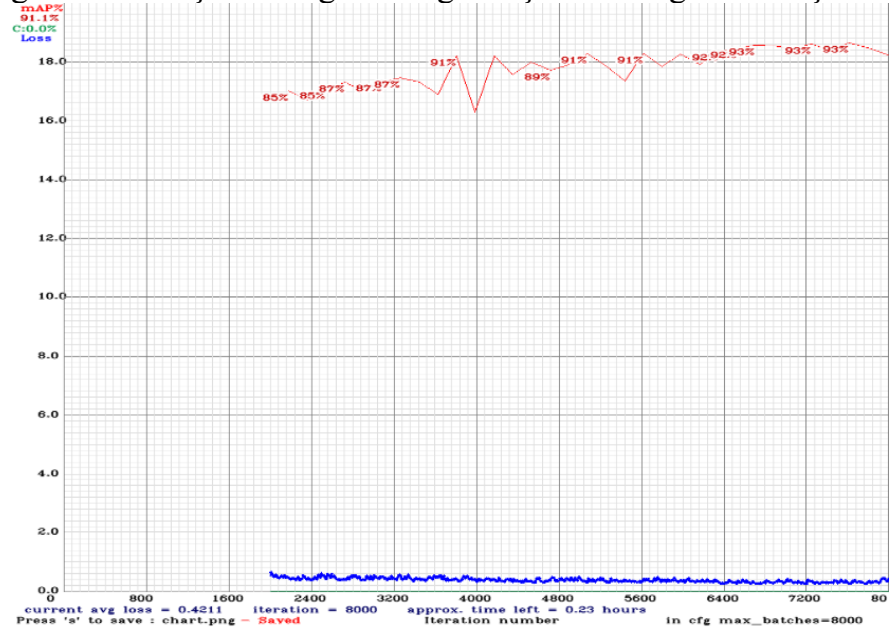

Şekil 6: YOLOv4 Eğitim Sonuçları

Mavi eğri, eğitim kaybı veya eğitim veri kümesindeki hata oranıdır. Kırmızı çizgi, modelin daha önce hiç görülmemiş bir veri kümesinde veya doğrulama kümesinde iyi bir şekilde tespit edip edemediğini kontrol eden ortalama kesinlik oranıdır. 


\section{Sonuç}

Test amaçlı eğitilen modeller, gerçek araç üzerinde test edildiğinde düşük sayıda veriyle hazırlanan modelin doğruluk oranının düşük olduğu ve görüntü kirletme algoritmaları uygulanarak veri çoğaltma yöntemleriyle hazırlanan modelin doğruluk oranının daha yüksek olduğu gözlemlenmiştir. $\mathrm{Bu}$ sayede insan müdahalesi olmadan nesne tespiti yaparak çalışan sistemlerin kazaya sebebiyet vermeden sorunsuz bir şekilde çalışmalarına olanak sağladığı saptanmıştır.

\section{Teşekkür}

Yazarlar ayrıca Konya Teknik Üniversitesi RAC-LAB Araştırma Laboratuvarı'na (http://www.rac-lab.com) teşekkür eder.

\section{Kaynakça}

[1] (2021) Kontrast Sinırlı Uyarlanabilir Histogram Eşitleme (CLAHE), [Online]. Available: https://github.com/YuAo/Accelerated-CLAHE

[2] FBochkovskiy, Alexey, et al. "YOLOv4: Optimal Speed and Accuracy of Object Detection." ArXiv:2004.10934 [Cs, Eess], Apr. 2020. arXiv.org,

[3] (2021) Image Filters: Gaussian Blur [Online]. Available: https://aryamansharda.medium.com/image-filters-gaussianblur-eb36db6781b1

[4] ŞEKER, Abdulkadir, et al. Derin Öğrenme Yöntemleri ve Uygulamaları Hakkında Bir İnceleme. 15 Nov. 2017. dergipark.org.tr,

[5] Meeus, Wim, et al. "An overview of today's high-level synthesis tools." Design Automation for Embedded Systems 16.3 (2012): 31-51.

[6] Yamashita, Rikiya, et al. "Convolutional neural networks: an overview and application in radiology." Insights into imaging 9.4 (2018): 611-629.

[7] Neubeck, Alexander, and Luc Van Gool. "Efficient nonmaximum suppression." 18th International Conference on Pattern Recognition (ICPR'06). Vol. 3. IEEE, 2006. 